\title{
DOI: 10.7596/taksad.v9i2.2351
}

Citation: Yunosova, V., Alekseeva, L., Hlazova, S., \& Shkola, G. (2020). Phenomenon of Sound Synesthesia in the Development of Students' Creative Thinking. Journal of History Culture and Art Research, 9(2), 147-164. doi:http://dx.doi.org/10.7596/taksad.v9i2.2351

\section{Phenomenon of Sound Synesthesia in the Development of Students' Creative Thinking}

\author{
Valentina Yunosova ${ }^{1}$, Larysa Alekseeva ${ }^{2}$, \\ Svitlana Hlazova ${ }^{3}$, Svitlana Kornienko ${ }^{4}$, Galyna Shkola ${ }^{5}$
}

\begin{abstract}
Changes in social, political and economic life, which have taken place very rapidly in recent years, are causing radical changes in various social spheres, in particular in higher education, the priority of which is the development of human subjective qualities that allow living in a changing world, changing oneself in it. In the modern educational paradigm, focused on meeting the needs of the individual, a special place is occupied by the problems of self-development, self-realization of a student. Therefore, it is advisable to use the phenomenon of synesthesia in the educational process. Today, the study of the phenomenon of synesthesia allows identifying the characteristics, to explain its potential in the development of human creativity. The relevance of the theory, methodology, and genesis of synesthesia is confirmed by changes in science itself, which again addressed the problem of person. The burst of research attention to the problem of synesthesia is due to the desire to find out the general principles of different ways of obtaining knowledge about the world, the desire to understand why such values can be realized in verbal, graphic, musical forms, awareness of the holistic nature of human thinking, which ultimately forms aesthetic worldview in representatives of different national and ethnic communities. One of the priority areas for the development of modern linguistics is the analysis of the sound organization of the text. In the framework of the proposed article, we focus on understanding the problem of the phenomenon of sound synesthesia in the creative thinking of students, which is a kind of additional mechanism for the perception and development of skills and abilities to analyze the sound and color relations in poetic text. The system-activity approach was applied in the work, which ensured the integrity, complexity, structure, and purposefulness of the research. With the help of appropriate methods synesthesia representations can be developed and used in the processes of learning and self-education, in learning foreign languages, creative activities and to compensate for disorders in sensory systems in people with psychophysical disorders. As a result of the study, it was found that the symbolism of sounds supports the semantic core of the meaning of language signs. Accordingly, sound synesthesia in the development of creative thinking of students will help to respond more quickly to the rapid changes taking place in the modern world.
\end{abstract}

Keywords: Sound, Color, Sound-color correlations, Synesthesia, Anthropocentrism, Phonosemantics, Sound symbolism, Universal models, Language picture of the world.

\footnotetext{
${ }^{1}$ Berdiansk State Pedagogical University, Faculty of Philology and Social Communications, Berdiansk, 4 Schmidtastr., 71100, Zaporizhzhia region, Ukraine. E-mail: yunosova@i.ua

${ }^{2}$ Berdiansk State Pedagogical University, Faculty of Philology and Social Communications, Berdiansk, 4 Schmidtastr., 71100, Zaporizhzhia region, Ukraine. E-mail: alekseeva.lara81@gmail.com

${ }^{3}$ Berdiansk State Pedagogical University, Faculty of Philology and Social Communications, Berdiansk, 4 Schmidtastr., 71100, Zaporizhzhia region, Ukraine. E-mail: svetglazova@gmail.com

${ }^{4}$ Berdiansk State Pedagogical University, Faculty of Philology and Social Communications, Berdiansk, 4 Schmidtastr., 71100, Zaporizhzhia region, Ukraine. E-mail: kornienkosvetlana17@gmail.com

${ }^{5}$ Kyiv National Linguistic University, Faculty of Slavic Philology, Kyiv, 73 Velyka Vasylkivska-str., 03680. E-mail: shkolagal8@gmail.com
} 


\section{Introduction}

The intensification of interdisciplinary researches based on a systematic approach is a defining feature of scientific knowledge at the current stage of science development. Such studies extend and deepen human cognition, contribute to the global dialectical process of integrating knowledge through their further differentiation (in such a way the integrative sciences as biochemistry, neurocybernetics, mathematical linguistics, etc. have emerged). The blurring of the boundaries between object and subject, between reality and text, real and virtual, stimulates the search for authentic discourses that are taking place today in various fields of research.

Language is a mirror of the outside world that reflects reality and creates its own picture of the world, specific and unique to each language and, accordingly, to the people, ethnic group, language collective, using the language as a means of communication. Language does not exist outside of culture as a socially inherited set of practical skills and ideas that characterize the way of life of representatives of different national and ethnic cultures.

Today, the theory and practice of language learning continues to seek new approaches to language education. Recently used communicative, cognitive, comparative, genetic approaches in the teaching methods of the native (Ukrainian, Russian, Bulgarian, Polish, etc.) language provide a good level of command of it at all levels of communication. However, the problem is that communicative approaches do not sufficiently take into account the specificity of language as a reflection of a system of cultural values, on the basis of which specific communities and behaviors of their members are built, as well as the specificity of speech activity as culturally conditioned speech behavior. The fact that each culture is uniquely reflected in the language is undeniable. It is widely accepted that ethno-linguistic models of the world reflect the cultural categories of a particular group, and that different languages model the world in their own way. Related cultures have similar linguistic foundations through similar cultural experiences.

\section{Literature review}

At the beginning of the third millennium, modern linguists are actively studying the question of the relation of the author's idiostyle with the individual language picture of the world, the aesthetics and pragmatics of the sound composition of the word in the artistic text, the linguostylistic features of artistic communication.

First consider the general understanding of synesthesia as a special phenomenon of human perception. The essence of synesthesia is that, under certain conditions, a combination of two or more sensations is created, resulting in the quality of one of them being transferred to another, and a new original sensation is created on the basis of a similar merger. The researchers argue that synesthesia is inherent in all forms of art, including music (works by K. Debussy, M. Rimsky-Korsakov, O. Messian, O. Skryabin), pictorial art (paintings by J. Belmont, A. Valensi, V. Kandinsky, M. Čiurlionis), literature (poems by A. Blok, F. Garcia Lorca, A. Rimbaud and P. Tychyna). Terms such as "musical painting", "light music", "color hearing" and "mix of sensations" appear in the scientific vocabulary.

In linguistics, the most widely represented studies are sound symbolism (phonetic symbolism) - one of the varieties of linguistic synesthesia.

Of particular interest is the literary (poetic) synesthesia, since it is, in fact, the verbal fixation of all possible intersensory associations that the writer has in sensory contact with the world. After all, in poetry, the word, as a signal of signals, can be heard and seen on a variety of levels: melody, color, plastic. This peculiarity, this special character of a concrete and sensual vision of the world, distinguishes poetry among other kinds of arts.

Experimental studies of human consciousness have revealed the existence of associative semantic fields, to which units united by a common concept belong. The natural ability of a person to 
associations and analogies suggests that the organization of associative human activity is realized by certain universal models that native speakers of different languages use. Therefore, these models can be considered as characteristic of all the languages of the world.

One of the tasks of modern education is to pursue philological studies to find out the peculiarities of the inner world of the creative individual through his / her speech, sound-color relations in expression of the idiosyncratic sensory features of the author's worldview. The study of synesthesia sound-color correlations is conditioned by the prospects of revealing in them the linguocognitive features of synesthesia education in view of the micro- and macro-context, the system of the authors' philosophical positions, diachronic and synchronic aspects.

The concept of our work involves the presence of interconnected concepts that contribute to the leading idea:

1. Methodological concept that involves the selection and interaction of fundamental scientific ideas and approaches to the study of problems that were based on in the research process. The phenomenon of synesthesia (Greek "Simultaneous sensation") has been studied in the realms of philosophy (Pythagoras, Aristotle, F. Aquinas, J. Locke, G. Leibniz, D. Diderot, J.-J. Rousseau, E. Condillac, E. Swedenborg, M. Merlot-Ponty), aesthetics (J.Archimboldo, L. Kastel, B. Bishop, V. Kandinsky, B. Galleyev, I. Gerasimova, I. Vanechkina, V. Brainin), psychology (L. Vygotsky, O. Luria, S. Rubinstein, H. Schiffman), including the transpersonal (S. Grof, G. Karelsky) and cognitive (R. Solso), literary studies (Sh. Bodler, A. Rimbaud, J. Casagrande, S. Castellano, I. Abdullin), linguistics (B. Whorf, S. Ullman, Y. Stepanov, O. Vasilieva, L. Stepanian, S. McKenzie).

The problem of the connection of sound and its meaning in the word has attracted our attention. A considerable number of works by domestic and foreign linguists is devoted to the study of this issue. In particular, L. Hinton, J. Ohala, M. Magnus, A. Gazov-Ginzberg, M. Almalekh, A. Vezhbytska, S. Voronin, A. Zhuravlev, A. Mikhalev, I. Pavlovs'ka, L. Prokofyeva V. Levytsky, A. Kalita, $\mathrm{N}$. Lvova dealt with this issue. However, despite the considerable amount of scientific researches, many theoretical and practical aspects of these issues remain debatable and need further research.

At present, three main approaches to the study of linguistic and speech means of synesthesia are being developed in linguistics: psycholinguistic (O. Luria, B. Wharf, V. Belyanin), linguosemantic (V. Sayenko, B. Galleyev), and linguocognitive (S. Day, Y. Shen, K. Breton Callahas), and there are also isolated linguosemiotic (S. McKenzie) studies of this phenomenon. Whereas psycholinguistic and linguistic approaches are characterized by relative unidirectionality in the study of the linguistic aspect of synesthesia, phonosemantic (V. von Humboldt, R. Jakobson, M. Grammon, K. Nirop, V. Pisani), lexical-semantic (V. Sayenko, V. Moskvin, T. Kovaleva, L. Stepanyan) and structural-semantic (S. Ullman, F. Wilright, O. Vasilyeva) directions are singled out. However, the current state of research on the lingual aspect of synesthesia is characterized by fragmentation, the absence of systemic theories that would explain the complex nature of synesthesia: from its neuropsychophysiological basis to the specific expression in the individual's speech. It is possible to solve these problems, provided that a comprehensive interdisciplinary approach to the study of this phenomenon is involved.

2. Theoretical component that defines the basic concepts, theories, ideas, positions, definitions that determine the understanding of the essence of the sound phenomenon of synesthesia, methods of forming an additional mechanism for the perception of synesthesia imagery of the poetic text by representatives of different cultures.

3. Technological concept involves the development of a science-based system of study of the sound composition of texts in different languages, characterized by a well-defined mechanism for calculating the quantitative composition of sounds, taking into account the features of their pronunciation in each of the literary languages. 
Methodological principles were followed during the study:

- Objectivity principle (taking into account factors that contribute to the formation and further development of intercultural communicative competence of a polylinguistic personality, the conditions under which the formation of a certain category of personality, the adequacy of research approaches and tools that allow to obtain true knowledge of the process of forming a polylinguistic personality, provide for the exclusion of subjectivism, unilateralism and bias in the selection and evaluation of facts obtained);

- Essential analysis principle (correlation in the studied phenomena, external, special and single, penetration into their internal structure, disclosure of conditions of use, functioning and factors of development and possibilities of their purposeful change);

- Genetic principle (consideration of technology of polylinguistic personality's formation by means of intercultural communication on the basis of the conditions' analysis of the studied phenomenon's origin, further development);

- Logical and historical principles (combination of studying the history of the object (genetic aspect), theory (structure, functions, relations of the object in its present state), prospects);

- Principle of conceptual unity of the study (explanation of the analyzed phenomenon, based on a common position, understanding of the essence and regularities of the educational process in educational institutions with a polyethnic contingent);

- Systematic nature principle (the specificity of the system is not limited to the features of the constituent elements, but is primarily related to the nature of their interaction. The main task is to know the nature, mechanism of intercultural communication, human relations and multiethnic society).

The analysis of linguistic material was carried out taking into account the principles of phonosemantics, which were distinguished by scholars who deal with the issue of sound symbolism (S. Voronin, A. Zhuravlev, V. Levitsky, L. Prokofiev, etc.).

1. The principle of arbitrariness of the language sign. This is the first and basic methodological principle of phonosemantics. It may also be referred to as the principle of motivation and nonarbitrariness between sound and meaning in a word. At the same time, a language sign means "a twosided material-ideal unit of a systematically organized language code, which arbitrarily, symbolically and conventionally captures a certain sense in a sensible perceived form and serves as a means of storing, receiving, processing and transmitting information" (Selivanova, 2006: 375). This principle contrasts with the principle of the arbitrary sign of F. de Saussure. The position of the scientist on the arbitrariness of the concept's connection with its acoustic image in language became an axiom of the semiotics of the twentieth century, but later it was revised. The linguistic sign is fundamentally arbitrary, but in "modern" synchrony it has a double essence: it is both arbitrary and non-arbitrary. The reason for such a duality is seen by the researcher in the duality of the very nature of the word: it constantly exists in two hypostases - reflective and communicative.

Generally speaking, sound symbolism in modern linguistics refers to the presence of nonarbitrary link between the sound and meaning of a word, between a sign and a symbol behind that sign (S. Voronin, Yu. Malenovsky, N. Totska).

2. The principle of determinism. This principle of phonosemantics in relation to the theory of speech imaging implies the conditionality of the sign aspect of the word by the meaning of the word.

3. The principle of reflection. At the phonetic linguistic level, the content of reflection is the meaning of the sound complex of a word (as an image, or in other terms, as an entity homogeneous 
with the concept), and the form of reflection is a linguistic sign (as the material shell of a word). Therefore, the linguistic sign is the form, the material side of the reflection inherent in person.

4. The principle of integrity. According to this principle, the primacy of the system as a whole over the components of the system is postulated. The focus is on the integrity of the objects' properties. Each element in the system is linked to its other elements; the description of each element is not self-contained, because the element is described not separately but with regard to its relationship with other elements of the system as a whole.

5. The principle of versatility (multifaceted principle). This principle implies both the "inside face" most complete three-dimensional, "voluminous" description of the sound system in three interconnected but independent plans - syntagmatic, paradigmatic, hierarchical, and the "outside" description of the integrity of the system with respect to its connection with the environment. The sound system is a set of interrelated phonetically motivated words. In turn, the word is central, but not the only element of the sound system. One of the most important features of this system is that it involves elements of a number of other levels - phonemes, morphemes and microtexts.

In order to identify key sound-color relationships in the studied poetic texts, the following methods were used: semantic and contextual analysis, text interpretation; conceptual modeling (for reconstruction of models of sensory and sensory-emotional concepts), conceptual analysis (for revealing linguocognitive mechanisms of formation of verbal-poetic synesthesia), archetypal analysis (for detection of unconscious and subconscious mental formations, which caused the formation of synesthesia images, quantitative analysis (to determine the dominant conceptual mechanisms of the sound-color correlations' formation; to determine the trend of the use of synesthesia images by authors), the method of comparative analysis (to identify common and distinctive features of synesthesia's imagery).

Consequently, sound symbolism (phonetic symbolism) is international in nature, and sound symbolic laws are statistical universals. This makes it possible to explore sound-color associativity using the same methods in different languages.

\section{Discussion}

Systematic studies in recent years have shown that the sounds of speech are meaningful (S. Voronin, A. Zhuravlev, V. Levitsky, L. Prokofiev). Even a special science stands out phonosemantics, the subject of which is the onomatopoeic system and sound symbolic speech system. Phonosemantics is born and manifests itself at the intersection of phonetics (expression plan), semantics (content plan) and lexicology (the set of these plans). There are two points of view on options for determining the occurrence of the symbolism of speech sounds. A. Zhuravlev singles out among them the so-called hypothesis of primary sound symbolism (it's in the fact that the symbolism of sounds is considered primary in relation to conceptual meaning; it's noted that it arose under the influence of natural sounds) and the hypothesis of secondary sound symbolism (V. Levitsky explains that secondary symbolism arises from the desire of speakers to find a correlation between the sounding of a word that develops according to phonetic laws and the meaning of the word (Levitsky, 2009). That is, if it is accidentally discovered that a particular sound occurs in several frequency words with similar semantics, then this semantics is generally projected onto the given sound, and now the sound, even taken separately, causes subconscious associations related to the semantics of these words (Zhuravlev, 1974: 23).

O. Espersen began the theoretical study of sound symbolism in the 1920s. His followers have worked out this problem in a theoretical way, as well as experimentally in different languages. The scientists have found deep psychological symbols in the sounds that connect language and thinking (R. Jacobson, O. Espersen, R. Piaget, etc.). 
In "Fundamentals of Phonosemantics" S. Voronin offers the most common definitions of the phenomenon of synesthesia in its broadest sense. Here are the definitions: 1) synesthesia is a phenomenon occurring in response to stimuli of secondary sensations and ideas of different quality; 2) joint work (of sensations), in which the features of sensations of one kind (e. g., auditory), are transferred to another type of sensations (e. g., visual), this phenomenon of transferring the qualities of one modality to another is called synesthesia; 3 ) synesthesia is a phenomenon of perception, which is in the fact that the impression corresponding to this stimulus and specific to certain organs of the senses is accompanied by another, additional impression or image, often by that which is characteristic of another modality (Voronin, 1982: 82-83).

Today, phonosemantics is being actively studied not only in Ukraine but also in the USA, Japan, many other countries in Europe and Asia. The scientists say that the basis of sound symbolism is common to all languages' psychophysiological laws. This suggests that there are universal qualities inherent in this associative relationship. However, each language has its own national specificity, which is related to the linguistic experience of its speakers. Therefore, when evaluating the sound side, for example, of the Russian poetry, representatives of another ethnic group may have associations that are rooted in the system of their native language, as well as cultural and social traditions inherent in the linguistic community. According to the researchers, the adequacy of perception in this case can only be achieved through training, because what the native speaker has intuitively, the speaker of another language must assimilate (Lyubimova, 1996: 76). However, according to L. Prokofieva, most of the information from the audio level of the text is "read" subconsciously or unconsciously. Therefore, it is problematic to speak about the conscious assimilation of the principles of this process (Prokofieva, 2007).

One of the most important issues of phonosemantics is the issue of the nature (nationality / universality) and nature (basis) of sound symbolism. Concerning the nature of sound symbolism, V. Levytsky notes that it is impossible to answer definitely to the question of whether the phenomenon of sound symbolism is universal. However, based on the experimental study of non-related languages, the existence of phonosemantic universals is proved, based on the universality of the articulatory characteristics of a particular sound and the ideas associated with them. At least, based on these studies, we can confidently state that there are statistically valid sound symbolic rules for related (IndoEuropean) languages, and for unrelated languages, certain universal tendencies in the symbolization of sounds have been identified.

There are also supporters of the theory of the national character of sound symbolism (among them V. Levitsky mentions I. Tylor). But this theory has received less confirmation today than the opposite one. In general, scientists have come to the conclusion that it is more appropriate to prove the universality of sound symbolism not at the level of phonemes, but at the level of smaller units, that is, acoustic / articulatory features.

One of the most common types of synesthesia is sound-color associations, which are the appearance in a person's mind of certain colors when perceiving sounds. It is advisable to emphasize the large number of studies that examine the mental load of various colors, the hidden information they carry for human consciousness, the psyche of the person who perceives them, and therefore the impact of these colors on the emotional state of the person. So, we have the following mechanism: a person perceives a certain combination of sounds by hearing or sight, each of which is associated with a particular color (depending on the peculiarities of the person's perception), colors in turn, cause further mental reactions, whether positive or negative.

Each color has a certain semantic content. Yu. Rudenko, using the results of researches conducted by famous psychologists and psycholinguists, gave the following characteristics to the colors: red - flame, power, danger, attention, will to win, sexuality, willpower; this color is exciting, 
active, energetic; green - unloading, peace, relaxation; this color is calm, gentle, transparent; yellow sun, fire, cheerfulness, will, ambiguity; this color is warm, sunny, cheerful, buoyant, attractive, fiery, invigorating; gray - indistinctness, balance, indifference, nobility, unpretentiousness; this color is calm, cool; purple - saturation, mystery, strength, superiority; this color is sad, mysterious, dark; brown purposefulness, stubbornness, accuracy; this color is strict, silent, calm, confident; black - sadness, danger, mourning, depth, independence; this color is mysterious, rich, harsh, honest; white openness, peace, purity, innocence; this color is joyful, attractive, light, boundless; blue (dark blue) calmness, sensuality, determination, inclination for empathy, ability to self-sacrifice, trust, dedication; this color is serious, calm, clear (Rudenko, 2009: 189-194). The Bulgarian professor M. Almalekh was actively involved in this issue. He convincingly proves that white means physical and mental purity, inviolability, red means fire, blood and more (Almalekh, 2012). It is interesting to note that in Bulgaria, on the first of March, on the feast of Baba Marta, red carpets and paths for silt, lofts, etc. are removed, for all living things flee from red (Mikov, 1985). This custom serves to protect against the evil forces and animals that woke up in early spring with all other wildlife. So color semantization is aimed at the cult of fire, deliberately used by humans to chase and destroy dangerous animals.

In Polish linguistics, color designation was studied by D. Budniak, R. Tokarski, A. Wierzbiecka, A. Zaushnits and others. In the field of researchers' view were also questions of comparative study of color names: in the Polish, Czech, Ukrainian and Russian languages (I. Belyaev); in Polish and Russian (D. Budniak); in Polish and Swedish (E. Petrak-Porvish and E. Teodorovich-Hellman).

Fiction in the creation of the image uses a word that has meaning, sound color and rhythm. Literature always strives for a picturesque picture of reality, having achieved much in the reproduction of landscapes, human portraits, interiors, still lives, battles and everyday scenes. This approach is accurately characterized by the expression "draw with a word." According to I. Franko ("From the Secrets of Poetic Creativity"), poetry and painting have a lot in common, especially in their perception. There is the difference between them: "When painting appeals only to sight and only indirectly, with the help of visual impressions, it awakens in our soul the images most commonly associated with this visual impression... poetry appeals at the same time to sight and to hearing, and further with the help of words and all other meanings [sensations], and it can evoke such images in our souls, which painting cannot cause in any way"; "The painter gives us the impression of colors, the poet evokes only the memories of colors; the painter appeals directly to the meaning, the poet to the imagination" (Franko, 1976: 103).

Having a common ultimate goal - artistic and aesthetic reflection of reality - poetry, painting and music reach it by various means. Painting appeals only to sight, and only by association with visual sensations it can conjure up in our imagination non-visual images: movement, heat, cold, sounds. In art there is even the term musical painting. The brightest representatives of this area are A. Valensi, V. Kandinsky, M. Čiurlionis. It is a historical fact that many pioneers of scenic abstraction viewed music as a model for new painting, as evidenced by both their theoretical works and their numerous titles. In particular, paintings by prominent Lithuanian artist and composer M. Čiurlionis are entitled: "Sonata of the Sun", "Sonata of the Stars", and the like. Their painting sounded, the colors corresponded to the rhythm of the music. It is known that the founder of abstract art - an artist, graphic artist and art theorist of the Russian origin V. Kandinsky was inspired for his abstractions by the music of Wagner and Schoenberg (in fact, Arnold Schoenberg also wrote paintings). Listening to "Lohengrin" by Wagner awakened in Kandinsky a kinesthetic sense of vision of colors and lines and prompted the idea that painting can develop the same forces that music has. Kandinsky compared each color of the spectrum to the sound of a musical instrument and expressed the conviction that colors and musical sounds by their nature evoke more subtle vibrations in the soul than words. He classified paints by their scents, sounds and shapes. For example, he thought blue was a circle, red was a square, yellow was a triangle. Thus, he created his paintings like musical symphonies, seeking harmony in the combination of colors. 
Music directly affects hearing and can only evoke acoustic sensations with the help of sound impressions: color, light ("color hearing" by composers O. Skryabin, M. Rimsky-Korsakov), movement, plastic (music by J. Haydn, V. Mozart, Ludwig van Beethoven). Poetry, through the imagination, appeals to the memory of the organs of sight, hearing, smell, touch, taste, and therefore uses all the means given separately to each of the other arts, which makes it a kind of universal, polysensory kind of art.

The synthesis of the arts is often understood as the organic combination or interconnection of expressive means of various kinds of art, which contributes to the aesthetic organization of the material and spiritual environment of person. That is why we consider it advisable to teach students synesthesia skills in classes in the cycle of philological disciplines. The use of color-semantic analysis in the interpretation of the text shows the importance for its semantic complex not only of sound interactions, but also of associative-synesthetic correspondences - holistic, and therefore universal for the process of generating meaning. Therefore, one cannot count on the completeness of comprehension of the whole semantic complex of artistic text, ignoring such correspondences, since they imbue any existence of sound, especially within the artistic system. At the same time, despite the large number of fundamental scientific studies in phonosemantics, the majority of interpretations of the artistic text occur at the level of lexical and grammatical units, and the color-matching and their semantic load remain unaddressed.

Synesthesia's experience of responding to the world expands the horizons of humanity. It relies on sensory syncretism, the use of synthesis in form-making, appeals to associative understanding of reality, analogy, inter-sensory association, etc. In the context of the rapid changes that are taking place now, such novelty makes it possible to better adapt to them because of the ability to go beyond the established, overcoming conservatism or stereotypes, etc.

When considering the problem of the transmission of sensual images in poetry, I. Franko rightly noted: "When a poet undertakes drawing, he does not do so exclusively with paints, which in his nature are only words, a clutch of such rustles and sounds, but touches our different meanings, it evokes in the soul images of heterogeneous impressions, but in such a way that they immediately merge into one organic and harmonious whole" (Franko, 1976: 101).

The sound in the poem plays an extremely important role, as if it were a mediator between the author - the world - the recipient. The image formed by the recipient is complemented by the impressions that arise from the acoustic potential of the sounds in the poem. Exploring the phonosemantic organization of poetic works by P. Tychyna, Yu. Malenovsky concluded that "the phonosemantic design of works by a poet is polyfunctional, which correlates with sound symbolism" (Malenovsky, 2003: 198). That is why we focus on students' perceptions of the sound features of the text.

A poetic work is a complex system, all levels and elements of which are interdependent or interconnected, organized in such a way as to fully serve the expression of the author's intention. In the parameters of poetic speech, quantitative and qualitative characteristics of the phonemic composition of words selected from the vocabulary of the language are important. Sound repetitions, increases in the frequency of individual sounds, which are neutral in expressive relation to other types of speech, are noticeable in the poetic work, and acquire functional significance, contributing to the embodiment of the aesthetic design of the author.

Speech sounds carry not only meaningful information about environmental parameters, but also cause certain color associations. The effort to install color-sound correspondence was first demonstrated by A. Rimbaud in the sonnet "Vowels":

A Black, E white, I red, U green, O blue: vowels,

I shall tell, one day, of your mysterious origins ... 
(translated by Oliver Bernard)

(Rimbaud, 1995: 210).

But such assumptions of the poet were purely subjective, deeply intuitive and hypothetical. The work of researchers of a later period was of scientific importance and validity.

A. Zhuravlev conducted a series of experiments on the Russian language material to identify the phoneme color value. He observed that low pitch sounds are mainly associated with dark tones, and high pitch sounds - with light ones. The researcher claims that the graphemes are clearly colored: a/я - red, o - light yellow or white, e/ $\epsilon$ - green, i/ŭ - blue, $y$ - dark blue, purple, ю - blue, lilac, $n$ dark brown or black (Zhuravlev, 1991: 102).

Exploring the basic problems of sound symbolism, it is not necessary to absolutize it and look for it in all words. In the language, according to V. Levitsky, not all words can be referred to as symbolic, but only predominantly polar concepts. Therefore, according to the scientist, sound symbolism is not absolute, but relative in nature, otherwise it would lose its expressive function (Levitsky, 2009).

According to A. Zhuravlev, the effect of sound color can be revealed only in the case when a certain color picture is created in the poem, and the drawing of the poems' vowel should "illuminate" this picture with sounds of the corresponding color. He emphasizes that the sound $\boldsymbol{a}$ in Russian is undoubtedly associated with red, as evidenced by experiments with thousands of informants.

Polish researcher M. Mołodyńska-Wheeler also proves that the sound [a] is colored in red (Mołodyńska-Wheeler, access mode: http://martamolo.com/txt/Synestezja- March\% 20Mo\% C5\% 82ody\% C5\% 84ska\% 20Wheeler.pdf).

If so, then it can be expected that the poems, which refer to certain phenomena and objects of red color, will emphasize the role of the vowel $[\boldsymbol{a}]$ - it will occur much more often than usual, especially in stressed syllables. This is the poetry that we have selected for analysis during our studies with philological students. Initially, they were asked to listen to an artwork, after which students had to paint (in imagination) a picture that would convey its meaning, and write in the exercise books the colors that dominate their paintings (imaginary). Only then they did the audio analysis of the text, calculating the total number of vowels and the percentage of each vowel's use.

To identify color associations, we analyzed the sound composition of poetry by different authors in four Slavic languages: Ukrainian, Russian, Bulgarian and Polish. Poetic works have been selected for the study because sound content is especially important in them. A. Zhuravlev's method was taken as the basis, but no sound letters were analyzed, but only sounds.

The method of calculation is as follows: in the recorded phonetic transcription of the text of the poem, the number of vowels is calculated. To take into account the special role of stressed vowels, they are doubled in the calculation. If there are short vowels in the language (as, for example, in the

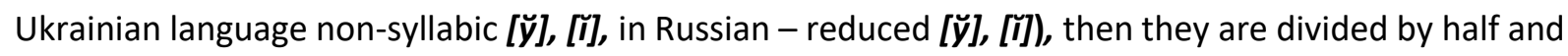
added to the vowels [y], [i], [a].

One of the most important features of Slavic vocalism is the pronunciation and vowel functions depending on the stress. In articulation and acoustic terms, the distinction between stressed and unstressed vowels is significant. The loud voices mostly sound distinctly and clear. Unstressed vowels are pronounced with less strain on the speech organs. It is for this reason that their pronunciation changes, which more or less removes them from the main sound, which is in the stressed position. However, in Polish there is no reduction of unstressed vowels. All Polish vowels are pronounced equally under stress and in the unstressed position.

In the phonetic system of most of the analyzed languages, there are 6 vowel phonemes, in particular: in Ukrainian - [e], [u], [i], [y], [o], [a]; in Russian - [э], [b], [u], [y], [o], [a]; in Bulgarian $[e],[b],[i],[y],[o],[a]$. There are 8 vowels in Polish - $[e],[y],[i],[u],[o],[a]$ and "nasal" $[e],[o]$, the presence of which differentiates Polish from Ukrainian, Russian and Bulgarian. 
In the Ukrainian language in a weak position, the vowels $[\boldsymbol{e}]$ and $[u]$ are pronounced as they approach each other; in Russian the sound [ $\left[\boldsymbol{\jmath}\right.$ ] is pronounced as [ $\left.\mathbf{u}^{\boldsymbol{*}}\right],[\mathbf{\Lambda}]$, and in Bulgarian they do not change their sounding. The vowel $[a]$ in Bulgarian in some endings is pronounced as [b] not only in a weak but even in a strong position, i. e. it changes its sound (Kornienko, 2012), whereas in the Ukrainian language it is always pronounced clearly and distinctively. In Russian, the sound [a] in a weak position is pronounced, depending on the previous consonant as $\left[\mathbf{u}^{3}\right],\left[\mathbf{b}^{3}\right],[\mathbf{b}],[\mathbf{b}]$. That is, it changes both qualitatively and quantitatively. [o] just sounds different in unstressed languages. In Bulgarian, the vowel [o] in a weak position is always approaching $[y]$, in the Ukrainian language it is approaching [y] only before the syllable with the next stressed [y]. In modern Russian, it can be pronounced as [ $\Lambda$ ], $\left[u^{\ni}\right],\left[b^{3}\right]$. The Polish vowels $[a],[e],[u]$ are pronounced similar to the corresponding stressed sounds of the Ukrainian language.

These and other audio differences are necessarily taken into account when calculating the frequency of the use of vowels in the poetic texts of different languages.

The results of our observations and work in the student audience proved to be quite unexpected and impressive for the latter. We have analyzed the poetry of various authors, referring to events related to red: war, fire, blood, autumn purple, red flowers and more. As the results suggest, in such texts, indeed, the sound [a] has a significant advantage, despite the differences in the pronunciation of vowels in different languages.

Consider, for example, an excerpt from the chapter titled "The Red Banquet" of Taras Shevchenko's poem "Haydamaky":

Закричали гайдамаки:

"Гине шляххта, гине!

Гине шляххта! Погуляє

Ta хмару нагрієм!"

Зайнялася Смілянщина,

Хмара червоніє.

(Haidamaki shouted:

"The gentry is dying, it's dying!

The gentry is dying! We'll take a walk

We'll heat the cloud!"

Smilyanshchyna took up,

The cloud is red).

(translated by Andriy Moroz)

Hereafter, in bold we mark the pronunciation of sound [a], with underlined - stressed [a].

Phonetic transcription of this text is transmitted in Ukrainian as follows:

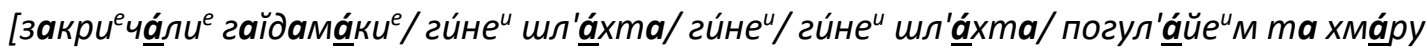

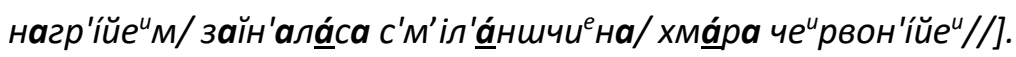

The ratio of vowels in the chapter "The Red Banquet" is transmitted by means of the diagram:

A - 103 (36\%)

$E-41(14 \%)$ 


$$
\begin{aligned}
& \text { U- } 39(14 \%) \\
& \text { I- } 34(12 \%) \\
& y-24(8 \%) \\
& o-45(16 \%)
\end{aligned}
$$

Therefore, the vowel [a] has a significant advantage in the analyzed text. In this connection, it is quite interesting to study the coloristic picture of the poem "Haydamaky" by T. Shevchenko. Scientists have found that to reproduce the real picture of the world (of the Sich, massacre, human torment and suffering), among the colorants in the poem "Haydamaky", the author uses primarily red among the chromatic colors (Diyak, 2013: 38). Therefore, the color coloration of the sound [a] coincides with the coloristic picture of the poem.

The results of quantitative counting of vowels in texts of different languages are shown in the diagrams:

\section{The Ukrainian language}

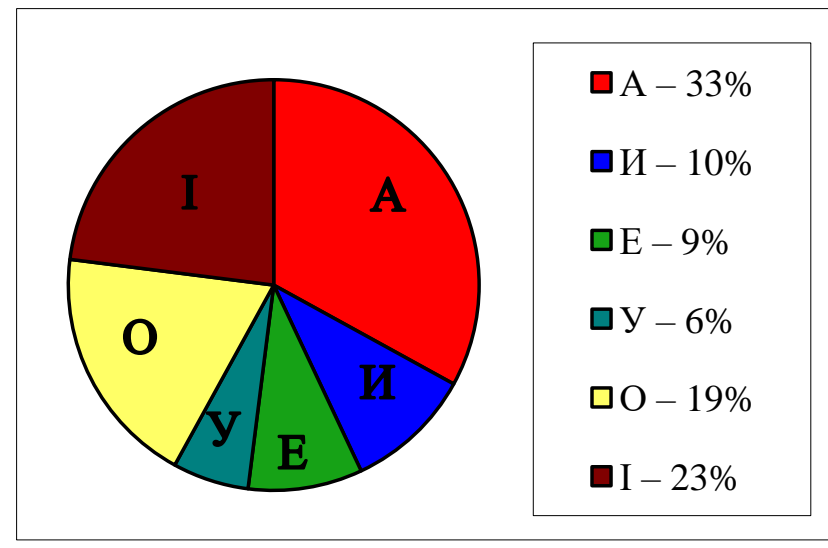

Volodymyr Sosyura

"The asters are conceived, the flowers are the last"

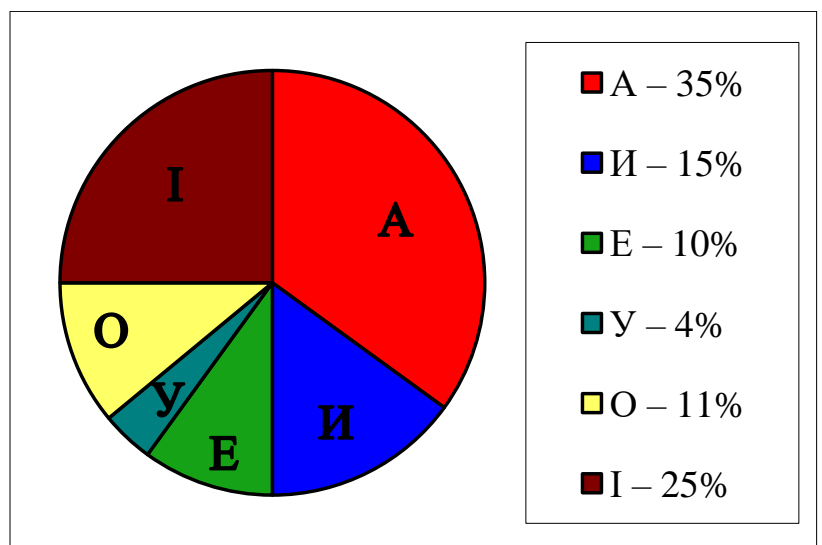

Anatoly Khromov

"War" 


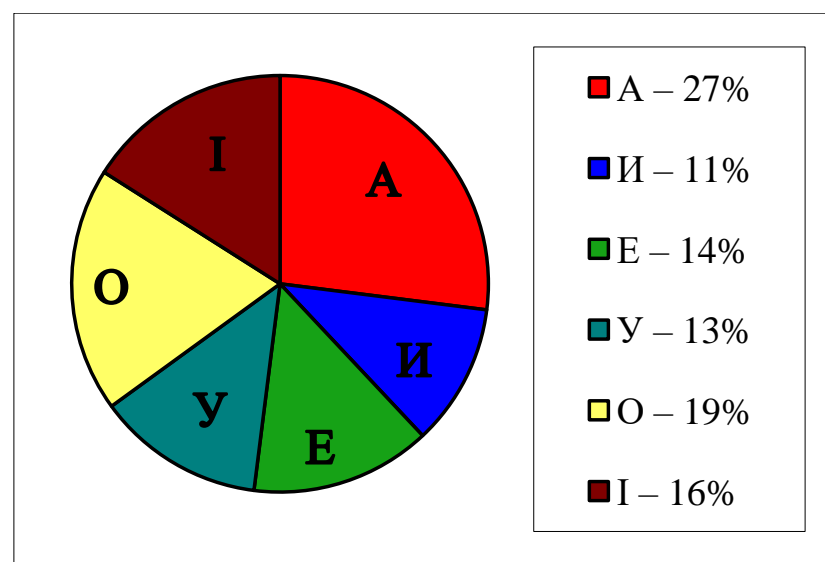

Lesya Ukrainka

"Your blood is a precious ruby"

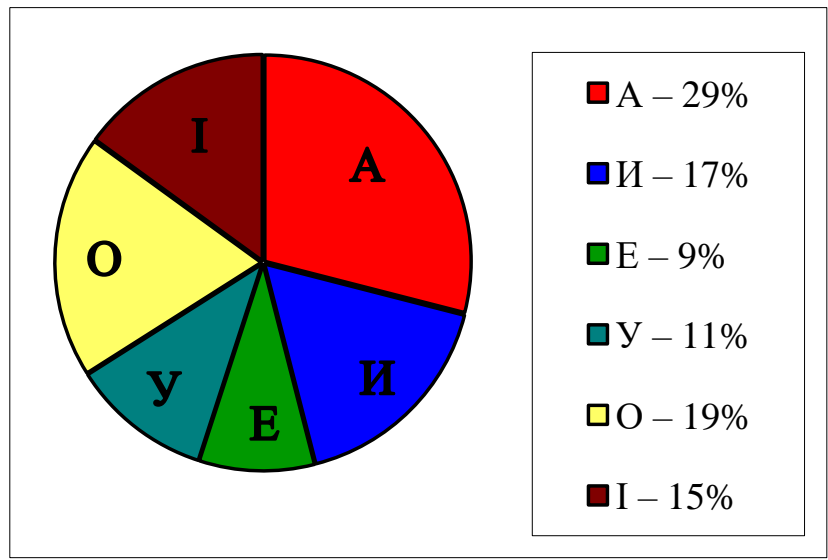

Lina Kostenko

"Berestechko"

The Bulgarian language

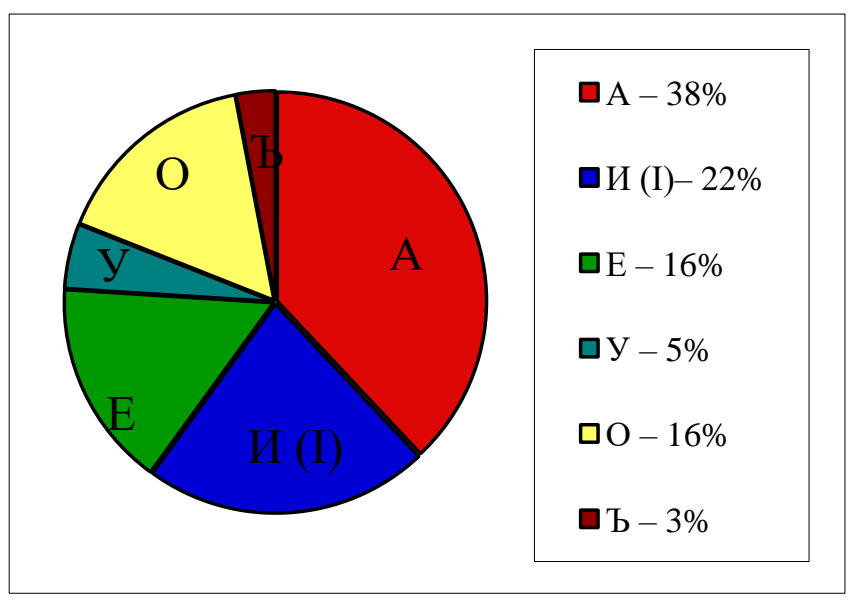

Hristo Petkov Botev

"Robbers" 


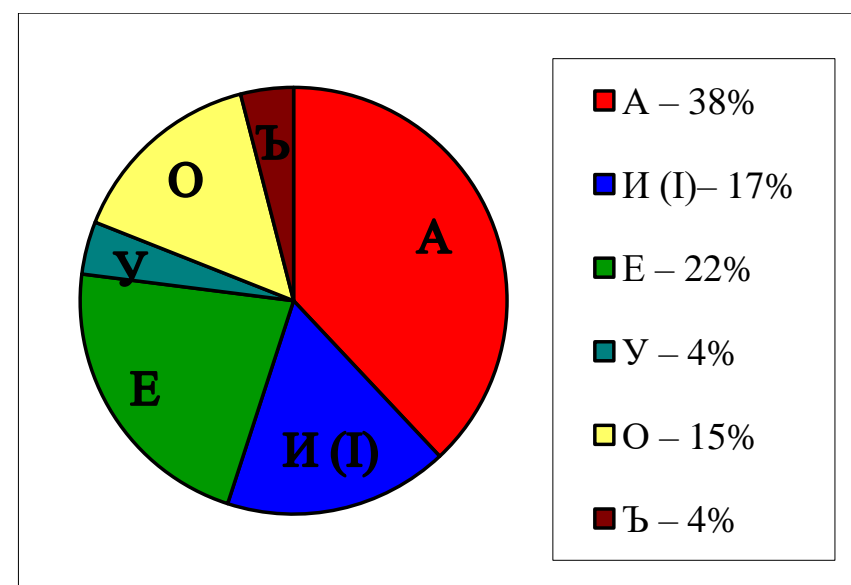

Stefan Nikolov Stambolov

"Voivode"

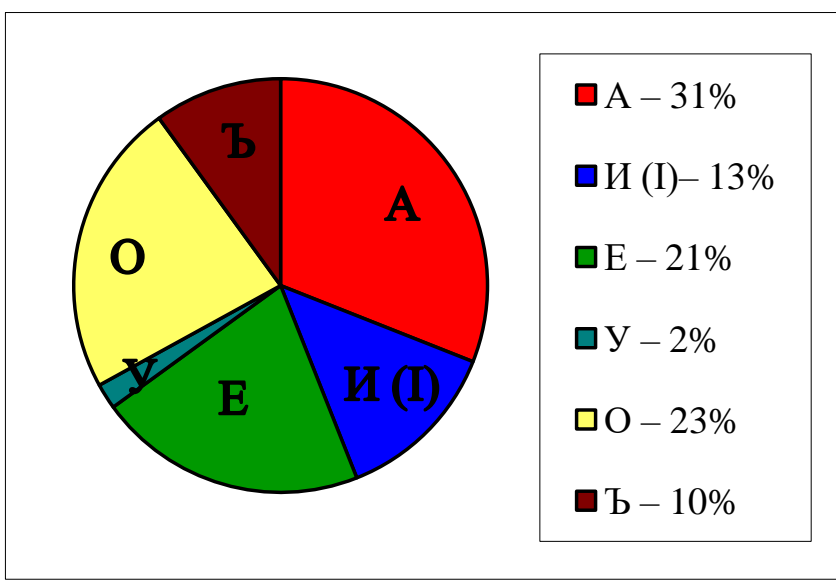

Peyo Yavorov (Peyo Totev Kracholov)

"Forward"

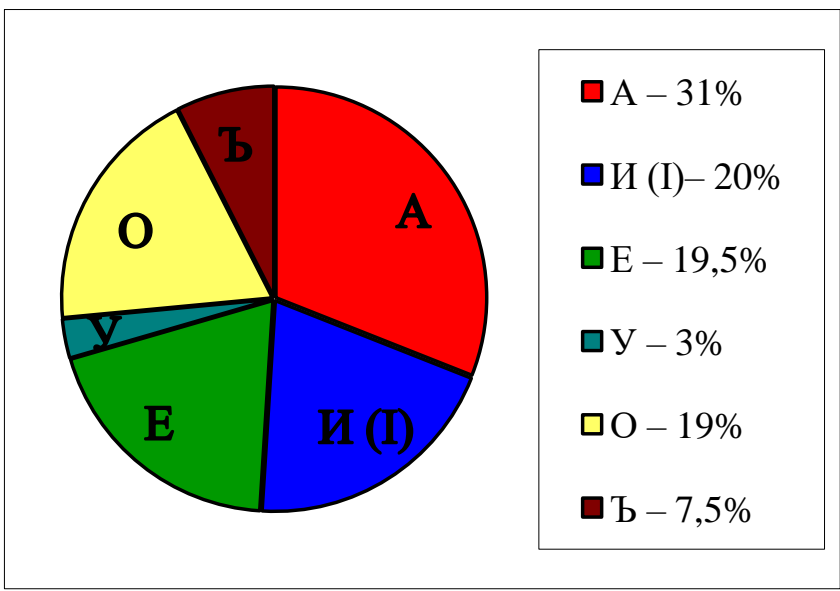

Elisaveta Bagryana

(Elisaveta Lyubomirova Belcheva)

"Descendant" 
The Russian language

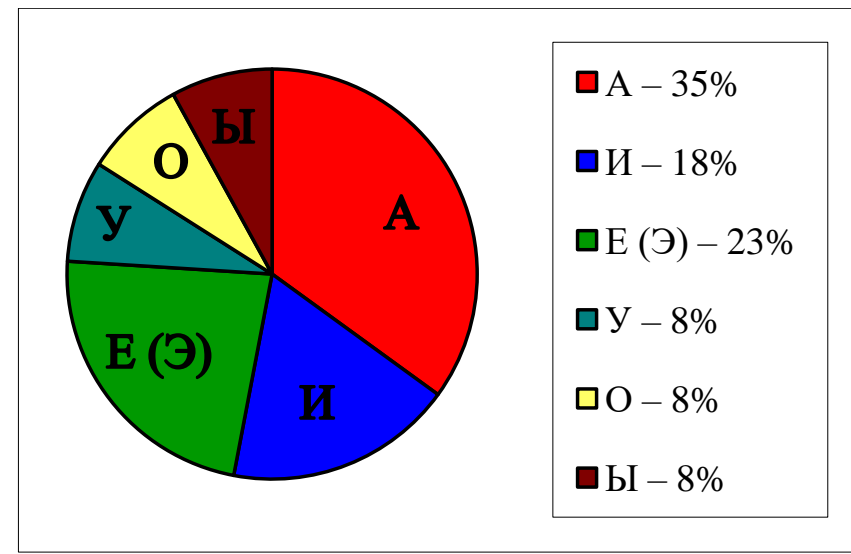

Vladimir Vysotsky

"Mass graves"

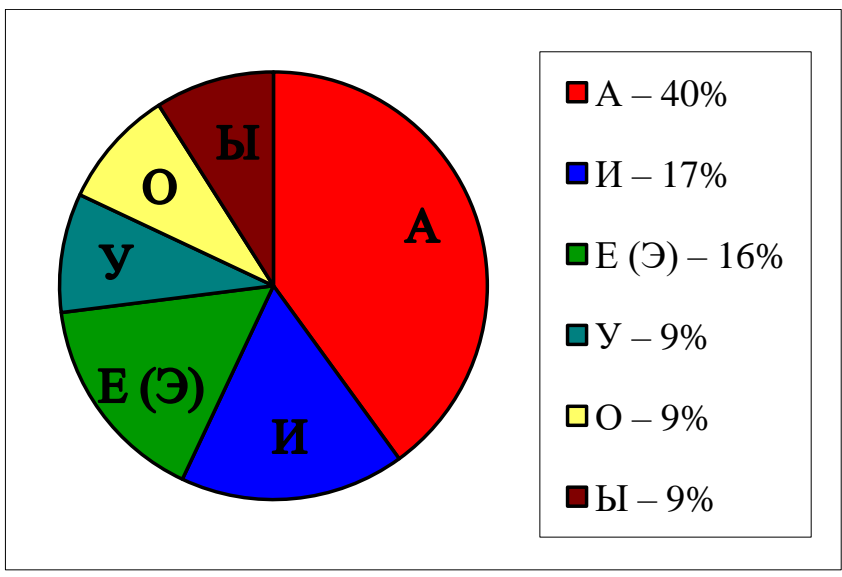

Alexander Block

"Gamayun, the prophetic bird"

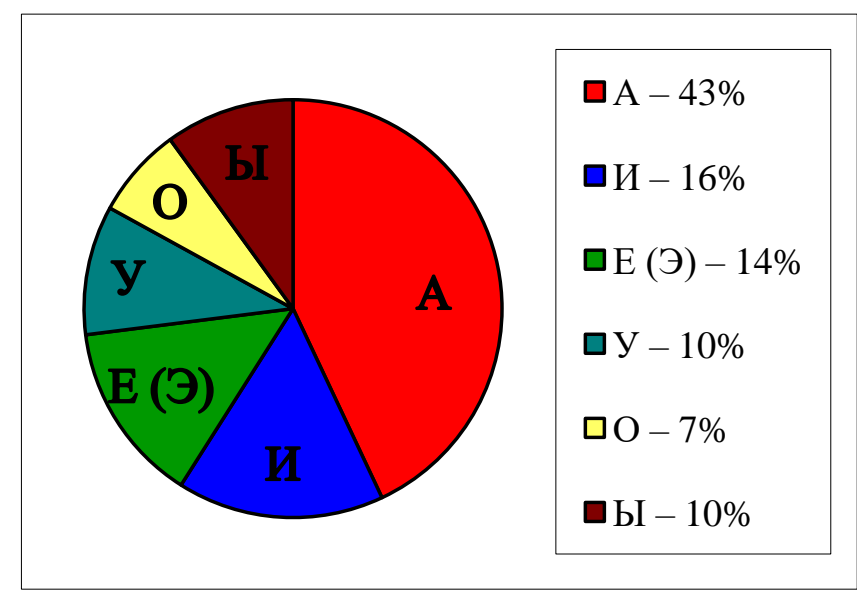

Arseny Tarkovsky

"Peter's Executions" 


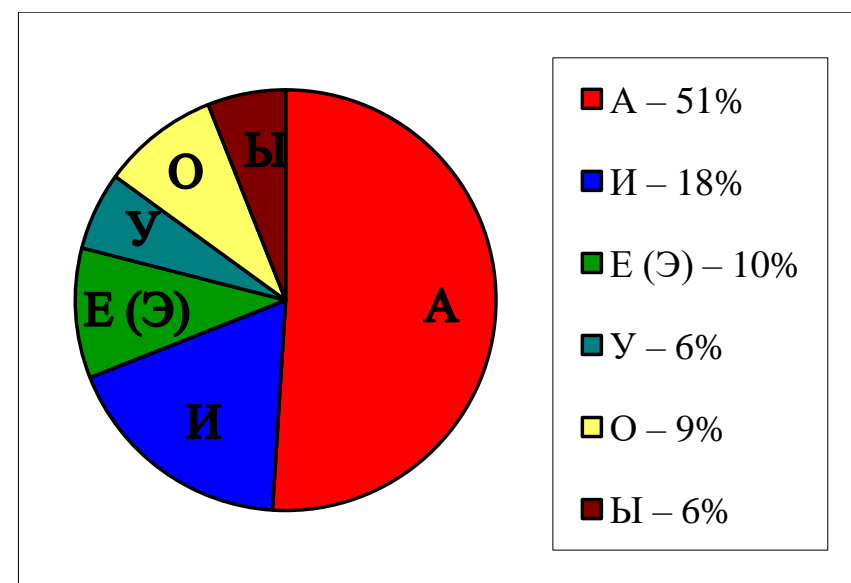

Andrey Voznesensky

"Fire at the Architectural Institute"

The Polish language

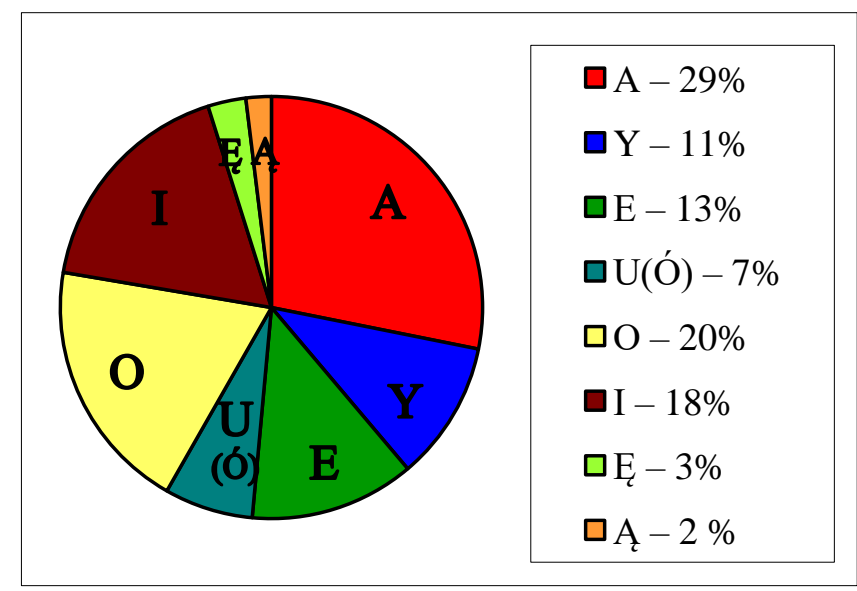

Julian Touwim

"Flowers of Poland"

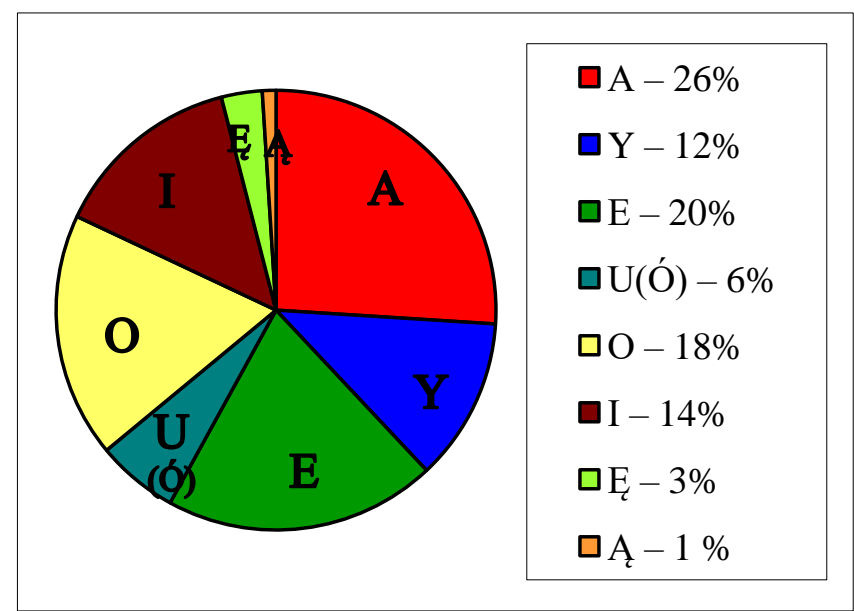

Tadeusz Ruzhevich

"The Survivor" 


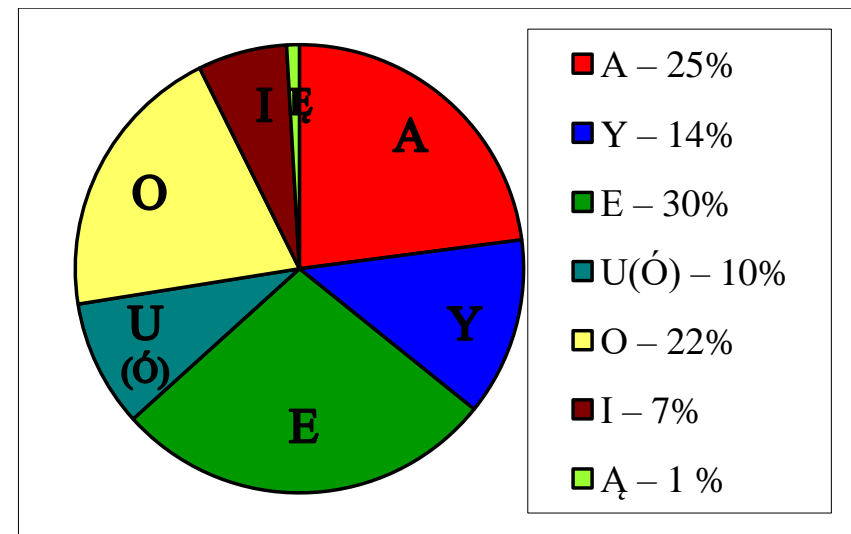

Casimira Zavistovs'ka

"Summer"

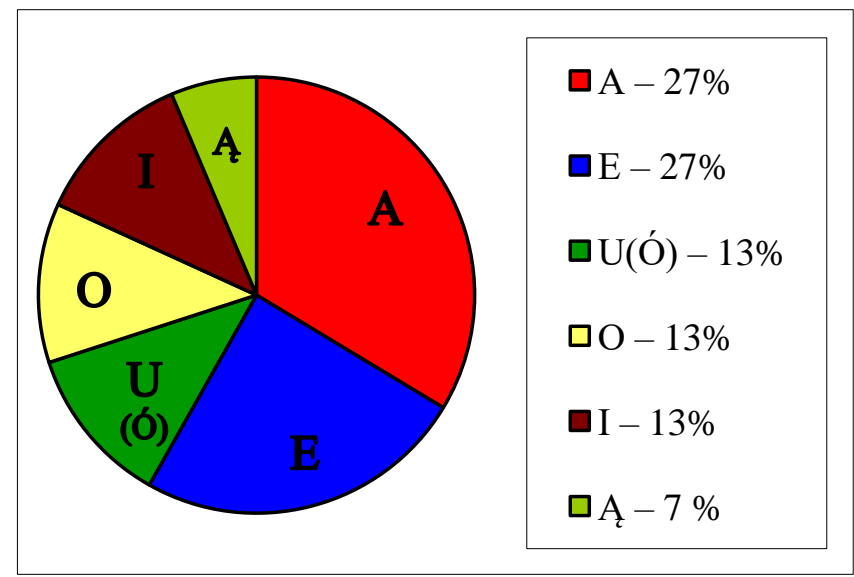

Kazimira Ilakovichuvna

"Battlefield"

According to the diagrams, in these cases, the symbolism of sounds is a reflection of the conceptual meaning of the word on its sound form. Therefore, the study found out that the sound image of the word represents additional information, supports the semantic core of the meaning of language signs.

It's important to mention that the dominance of red is preserved even when translating poetry into another language. In particular, in the poem-appeal "To the common man", the Polish poet Julian Tuwim opposed those who, with the aim of enrichment, were interested in fomenting war.

Sound's [a] frequency is $29 \%$.

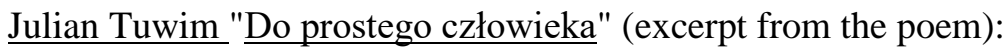

Rżnij karabinem w bruk ulicy!

Twoja jest krew, a ich jest naffta!

I od stolicy do stolicy

Zawołaj broniąc swej krwawicy:

"Bujać - to my, panowie szlạchta!"

In the Ukrainian translation by Gregory Kochur, the frequency of sound's [a] use is $27 \%$. 
О брук трощи приклад рушниці!

Бо кров твоя, а їхня наффта!

І від столиці до столиці

Гукни на всі ти їх марниці:

"Нем므 дурних, панове шляххта!"

(Smash the butt of the gun on the cobblestones!

For these are your blood, and their oil!

And from the capital to capital

Shout at all their nonsense things:

"We are not fools, you noblemen!")

(translated by Andriy Moroz)

Such cases testify to the universality of the phenomenon of synesthesia and the importance of a comprehensive study of its various manifestations, since the syncretization of different in origin sensations surprisingly harmonizes the external world with the inner world of person, causing a great number of memories, building associative chains, mixing instantaneously auditory, visual, olfactory, tactile impressions, painting a picture with different colors, creating tangible, sensory-specific images (Alekseeva \& Hlazova, 2019).

The analyzed tools form a coherent, three-dimensional perception that enables the listener to receive information and aesthetic satisfaction. The image formed by the recipient is complemented by the impressions that arise from the acoustic potential of the sounds in the poem.

\section{Conclusion}

Our analysis of scientific literature and experimental studies give grounds to argue that the full disclosure of the semantic complex of the artistic text is impossible without relying on sensory syncretism, appeals to associative understanding of reality, analogies, etc. To understand an object means to discover it in its entirety. When all levels of the system under study become available as a result of the experience of such analysis, it is possible to consider in the text what has not been noticed before. In addition, painstaking work on words, sounds, ability to see certain symbols in them develop a sense of beauty, shapes and organizes the ability of the human imagination in its highest and complex manifestations, develops the ability to immediately capture the general meaning of events from some detail. This is the internal logic of interconnecting the part and the whole. The ability of students to focus on certain features of reality, the ability to actively analyze the sensory facts contribute to the development of conscious ideas in them, which eventually helps to transform contemplation and conception into active forms of creative development of the world. This is extremely important, because in all spheres of human activity (individual and social), all new, creative assets begin with specific personal initiatives that are purely subjective. Developing students' creative thinking will help to overcome conservatism and stereotypes, enabling them to respond more quickly to the rapid changes that are taking place in the modern world.

A further perspective of the study is to find out the color coloration of other vocal sounds in different Slavic languages and to improve the methods of teaching students of sound color correlations. 


\section{References}

Alekseeva, L., \& Hlazova, S. (2019). Metaphorical constructions in speech-making by symbolists as a typical manifestation of synesthesia. Development Strategies and Priorities of the Philological Sciences: Proceedings of the International Scientific and Practical Conference, Zaporizhzhia, October 18-19, 2019, 7-11. Zaporizhzhia.

Almalekh, M. (2012). Color language grammar and sound. Nuova Bulgarian Studies, Yearbook of the New Bulgarian Studies Department, 2, 1-21.

Belyaev, I. (2005). Non-Basic Color Names In Polish, Czech, Russian or Ukrainian. Warsaw.

Budniak, D. (1987). A study of the confessional connectivity of Russian and Russian words that mean color. Opole.

Diyak, O., \& Diyak, Ya. (2013). Colorful picture of Taras Shevchenko's poem "Gaidamaki". Scientific journal of MP Dragomanov NPU. Series 10: Problems of Grammar and Lexicology of the Ukrainian Language, 10, 36-39.

Franko, I. (1976). Collection of works: in 50 vols. Vol. 31. Literary Critical Works (1897-1899). Kyiv.

Kornienko, S. (2012). Spelling and pronunciation of vowels in Bulgarian literary language: norms and deviations. Bulletin of Zaporizhzhya National University. Philological Sciences, 1, 252-259. Zaporizhzhia.

Levitsky, V. (2009). Sound symbolism. Myths and Reality. Chernivtsi.

Liubimova, N., Pinezhaninova, N., Somova, E. (1996). Sound metaphor in poetic text. Saint Petersburg. $144 \mathrm{p}$.

Malenovsky, Yu. (2003). Phonosemantic organization of a poetic work: an aspect of reception (based on the material of Paul Tychyna's poetry): Ph.D. thesis: 10.02.01 "The Ukrainian language". Kyiv.

Mikov, L. (1985). First March Rituals. Bulgarian Holidays and Customs. Sofia.

Mołodyńska-Wheeler, M. Synesthesia - practical implications at work of an English musician. URL: http://martamolo.com/txt/Synestezja-Marta\%20Mo\%C5\%82ody\%C5\%84ska\%20

Wheeler.pdf.

Pietrak-Porvish, G. (2006). White semantics in Polish and Swedish. Studia Linguistica Universitatis lagellonicae Cracoviensis, 123, 135-154.

Prokofieva, L. (2007). Sound-color associativity: universal, national, individual. Saratov.

Rimbaud, A. (1995). Drunken ship. Kyiv.

Rudenko, Yu. (2009). The use of the phenomenon of synesthesia as an ergonomic tool in the process of forming skills and reading skills in future preschool educators. Science and education, 7, 189-194.

Selivanova, O. (2006). Modern linguistics: a terminological encyclopedia. Poltava.

Teodorovich-Hellman, E. (1997). The names of the shades are Swedish and they are comparable in Polish. Semantic Structure of Vocabulary and Expressions / red. Grzegorchykova, R., \& Zaron, Z.. Warsaw. 103-112.

Voronin, S. (1982). The basics of phonosemantics. Leningrad.

Wierzbicka, A. (2005). There are no "color universals» but there are universals of visual semantics. Anthropological Linguistics, 47, 2, 217-244.

Zhuravlov, A. (1974). Phonetic meaning. Leningrad.

Zhuravlov, A. (1991). Sound and meaning ( $2^{\text {nd }}$ ed.). Moscow. 